\title{
The changes in the microstructure of ion-exchanged clays
}

\author{
Edyta Nartowska ${ }^{1, *}$, Tomasz Kozłowski ${ }^{1}$, and Marta Kolankowska ${ }^{1}$ \\ ${ }^{1}$ Kielce University of Technology, Faculty of Environmental, Geomatic and Energy Engineering, \\ Division of Geotechnical and Hydraulic Engineering, av. 1000-lecia Państwa Polskiego 7, 25-314 \\ Kielce, Poland
}

\begin{abstract}
Three natural bentonites and their monoionic forms were investigated by the X-Ray Diffractometry (XRD) and Scanning Electron Microscopy (SEM). SEM photographs were analysed using the Photoshop CS4 software and the pore parameters were calculated. The parameters were compared to a interplanar spacing d001 value changes between different homoionic forms. The results suggest the connection between the type of exchangeable cation with the structural parameters of the pores and physicomechanical parameters of the soil, therefore the ion exchange method could be used for controlling soil properties corresponding to their suitability for use in the industry.
\end{abstract}

\section{Introduction}

Recently, there has been growing interest in the application of clays to environmental engineering, environmental protection engineering and industry. Bentonites are a special group of clays, consisting essentially of the crystalline structure montmorillonite, which is responsible for a plasticity, thixotropy, high degree of swelling, particular expansive properties of the soil and a high potential adsorptivity to water. Thanks to the unique properties, bentonites are used e.g. for stabilizing boreholes and deep earthworks, in building guardrails while storing radioactive waste and for removing the toxic and radioactive contaminants from the environment and also for halting the spread of the pollution in the soil, water and air. Some characteristics of the soil, such e.g. clay fraction affect to their engineering parameters [1]. Also, connections between the type of exchangeable cation and soil mechanical properties [2,3] and changes in microstructural parameters $[4,5]$ are confirmed. Despite this, looking for the connections between the microstructure features with the soil properties is very essential.

Homoionic forms of the bentonites were examined with respect to thermal properties [6] and unfrozen water content [7]. In both cases a significant impact of the type of exchangeable cation on the studied parameters was confirmed.

The aim of the study was to determine the changes in the microstructure of clays after the ion exchange, which may affect the properties of the clay soils and thus their suitability for use in a specific areas of engineering and industry.

*Corresponding author: enartowska@tu.kielce.pl 


\section{Materials}

Research material consisted of three model soils: two clays of the Clay Minerals Society SWy-2 from Wyoming and Stx-1b from Texas and one clay BSvk from Jeslovy Potok, Slovakia deposits (imported to Poland by the ZGM Zebiec in Zebiec near Starachowice) and their homoionic forms $\left(\mathrm{Na}^{+} / \mathrm{K}^{+} / \mathrm{Fe}^{3+} / \mathrm{Ca}^{2+}\right)$, obtained from natural soils by the repeated saturation of the fraction less than $0.063 \mathrm{~mm}$ and subsequent purifying from the solutes by diffusion. The natural forms of clays are characterized by a high montmorillonite content of $85 \%$. Such soil are called 'bentonites'.

A properties of the thirteen tested soils are characterized in Table 1 and Table 2.

A preliminary analysis revealed that external surface area and specific surface area depends on the type of exchangeable cation. For $\mathrm{Ca}^{2+}$ form of the bentonites there was an increase in external and specific surface area whereas for $\mathrm{Na}^{+}$and $\mathrm{K}^{+}$forms a decrease in external and specific surface area was observed. A plastic limit was higher after the ion exchange, regardless of the cation type. Clay fraction content after the ion exchange was dependent on the soil type (regardless of the cation type): it decreased for SWy-2 bentonite and increased for Stx-1b and BSvk bentonites. The reason for similar behaviour of the bentonites from Texas and Slovakia could be a similar content of the major metals after the ion exchange (Table 2). bentonites from Texas and Slovakia are characterized by several times lower content of the $\mathrm{Na}^{+}$, three times greater content of the and about two times greater content of the $\mathrm{Ca}^{2+}$ than $\mathrm{SWy}-2$ bentonite. In turn, Bentonite from Wyoming has a two times greater content of the $\mathrm{Ca}^{2+}$ and five and seven times lower content of the $\mathrm{Na}^{+}$ and $\mathrm{K}^{+}$, respectively.

It appears that a decrease in the clay fraction content is associated with an increase in $\mathrm{Ca}^{2+}$ cation content in bentonites, what is surprising compared to an increase in external and specific surface area in these soils. This may indicate that a montmorillonite content, being a part of the clay and silt fraction contents, determines a specific surface area of the soil. Adictionally, a probably reason for changes in soil properties could be the differences of the planar-assign distance in a phase of montmorillonite $15 \mathrm{~A}$ and crystallinity between bentonites with different leading cation.

This observation may be relevant for engineering calculations of the colloidal activity according to Skempton, which depends only on clay fraction content. There is a need to further research towards the method of the determination of the parameters forming the part of formula for colloidal activity (mainly liquid limit and clay fraction content).

\section{Methodology}

\subsection{X-Ray Diffraction (XRD)}

X-ray diffraction analysis was conducted by using a Bruker D8 advance powder diffractometer in Debye- Sherrer geometry, $\mathrm{Cu}-\mathrm{K} \alpha_{\alpha 1}$ radiation $(\lambda=1,5406 \AA)$ from a Johansson-type monochromator and LynEye position-sensitive detector. The measurements were carried out at $2 \theta$ from $4.51^{\circ}$ to $70^{\circ}$. The applied voltage $3540 \mathrm{kV}$ with the $530 \mathrm{~mA}$ current.

Phase identification was made based on the database PDF 4+ whereas the estimation of the individual phases was made using a semi-quantitative method in Diffrac Eva program. The main purpose of the XRD study was to determine 001 planes i.e., the planes parallel to the surface of the sample. 

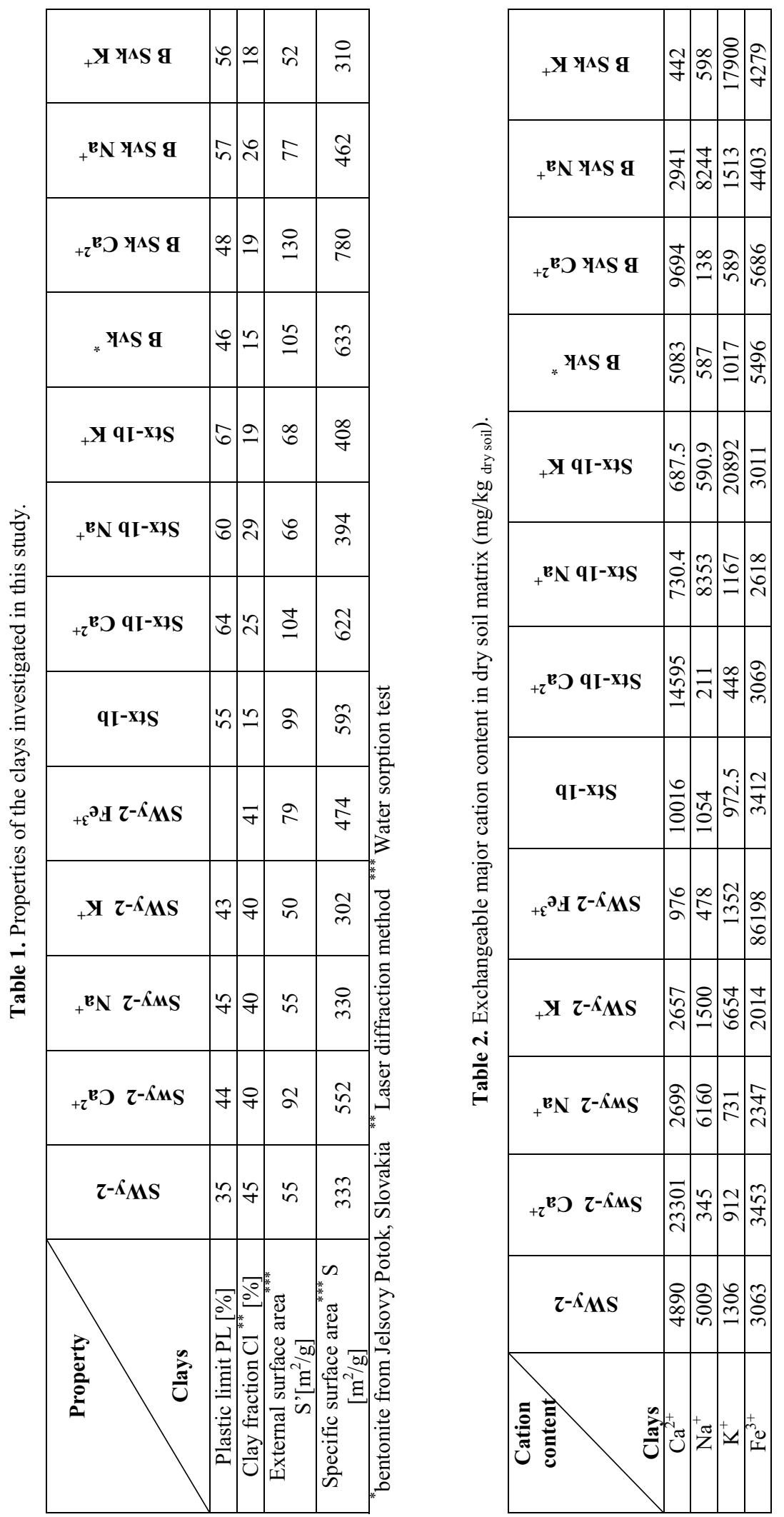


\subsection{Scanning Electron Microscopy (SEM)}

The experiments were conducted with a Quanta 200 scanning electron microscope at $10 \mathrm{kV}$ voltage applied. The air-dried samples $(8-10 \mathrm{~mm}$ diameter $)$ of the monoionic bentonites were observed and their microstructures were analyzed.

The surfaces of the samples were covered with a $40 \mathrm{~nm}$ layer of gold to prevent electrisation and photographed at two magnifications: x1000 and x5000. The photographs taken at the lower magnification were used to determine the quantitative pore space parameters, whereas the qualitative analysis of the soil microstructure and the types of contacts were based on the photographs taken at x5000 magnification.

The SEM photographs were analysed with Photoshop CS4 - based Numerical Image Analysis (NIA) method. Since the lighter areas on the SEM images of the soils correspond to the mineral particles, while darker areas - to the spaces between the particles, it is possible to identify pores and soil particles and to define the total surface area, height, perimeter, width and the total number of pores. Additional values required for the quantitative analysis, such as the number of ultra/micro pores, were calculated using Excel.

Pores are very important elements of the soil structure: e.g. they store water and affect its transport between the soil particles.[8]. Pores can be classified by size according to Grabowska-Olszewska [9]:

- ultrapores $<0.1 \mu \mathrm{m}$ - completely filled with the bound water

- micropores 0.1-10 $\mu \mathrm{m}$ - possible capillarity, filtration

- mezopores $10-1000 \mu \mathrm{m}$.

\section{Results}

\subsection{XDR results}

The peak positions at $2 \theta$ and X-ray counts for the natural bentonites and their homoionic forms are shown in figures 1-3. Table 3 shows interplanar spacing d001 values i.e. planes parallel to the sample surface.

For homoionic forms of the SWy-2 bentonite, there was a reduction in the value of the $2 \theta$ angle compared with the base material and, according to the Bragg equation, an increase of d001 value.

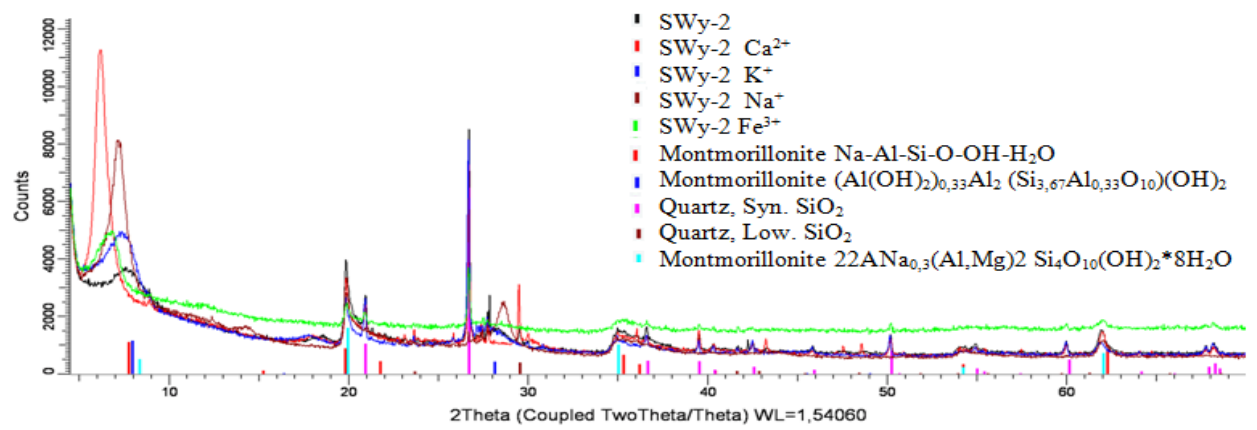

Fig. 1. The peak positions at $2 \theta$ and X-ray counts for the natural SWy-2 bentonite and its' homoionic forms.

In the case of homoionic forms of the STx-1b bentonite, there was an increase in the $2 \theta$ angle relative to the base material and a reduction of $\mathrm{d} 001$ values. 


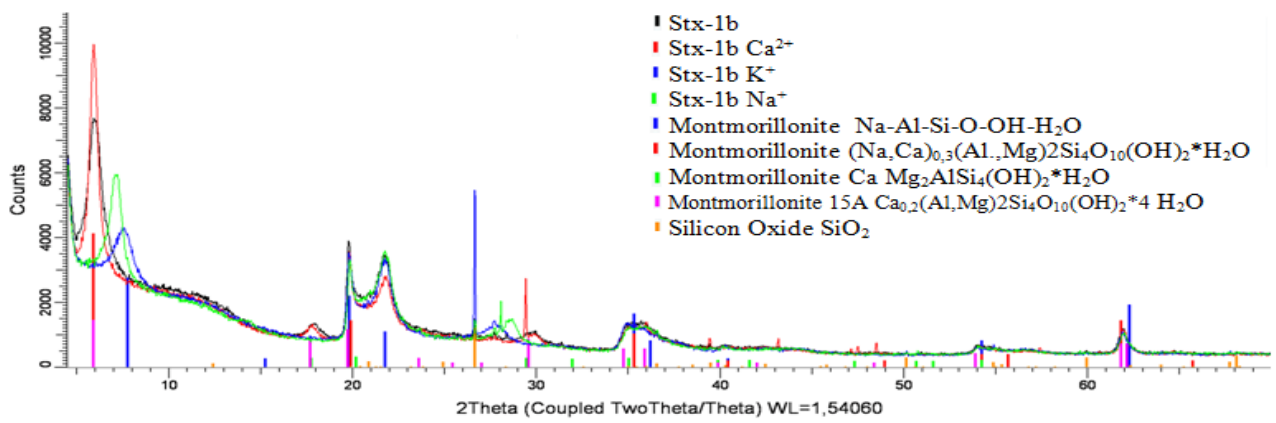

Fig. 2. The peak positions at $2 \theta$ and X-ray counts for the natural STx-1b bentonite and its' homoionic forms.

For homoionic forms of the BSvk bentonite there was an increase in the $2 \theta$ angle compared with the base material and reduction the interplanar spacing d001 values.

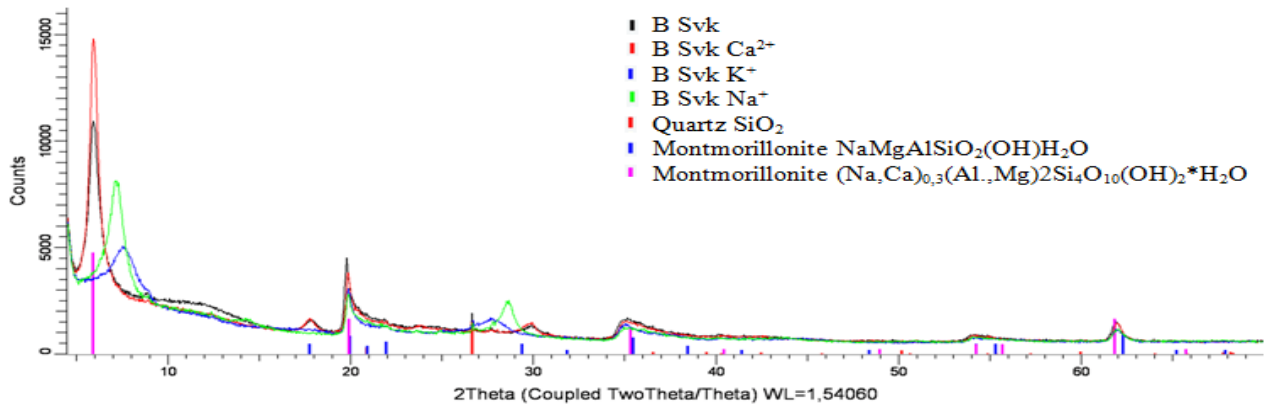

Fig. 3. The peak positions at $2 \theta$ and X-ray counts for the natural BSvk bentonite and its' homoionic forms.

Table 3. Collected interplanar spacing d001 values (parallel to the sample surface).

\begin{tabular}{|c|c|c|c|}
\hline \multirow{2}{*}{ Type of form } & Stx-1b & SWy-2 & BSvk \\
\cline { 2 - 4 } Clays & \multicolumn{3}{|c|}{$\mathrm{d} 001[\AA]$} \\
\hline base & 14.88 & 11.44 & 14.87 \\
\hline $\mathrm{Na}^{+}$ & 12.37 & 11.95 & 12.27 \\
\hline $\mathrm{K}^{+}$ & 11.66 & 11.86 & 11.56 \\
\hline $\mathrm{Ca}^{2+}$ & 14.84 & 14.33 & 14.88 \\
\hline $\mathrm{Fe}^{3+}$ & - & 13.26 & - \\
\hline \multicolumn{3}{|c}{} \\
\hline
\end{tabular}

\subsection{SEM photographs' analysis}

The photographs of the bentonite microstructures are shown in Fig. 4-6.

Microstructural analysis [10] of the 5 ion-varieties of the SWy-2 bentonite reveals an almost two-fold increase in the total surface area of the pores for $\mathrm{Na}^{+}$modification and twofold and three-fold decrease in the total area of the pores in/for $\mathrm{Ca}^{2+}$ and $\mathrm{Fe}^{3+}$ varieties compared to the natural bentonite. Also, a more than four-fold decrease in the number of ultrapores was observed for all the monoionic forms of the bentonite SWy- 2 .

Ion exchange of STx-1b bentonite caused the significant decrease in the total area of the pores. The largest decrease (4.5-fold) was obtained For the $\mathrm{Ca}^{2+}$ form. Aditionally, $\mathrm{K}^{+}$and $\mathrm{Ca}^{2+}$ bentonite forms were characterized by fewer ultrapores and micropores, whereas in the case of the $\mathrm{Na}^{+}$form, an increase in the numbers of ultrapores and a decrease in the number of micropores were observed. 


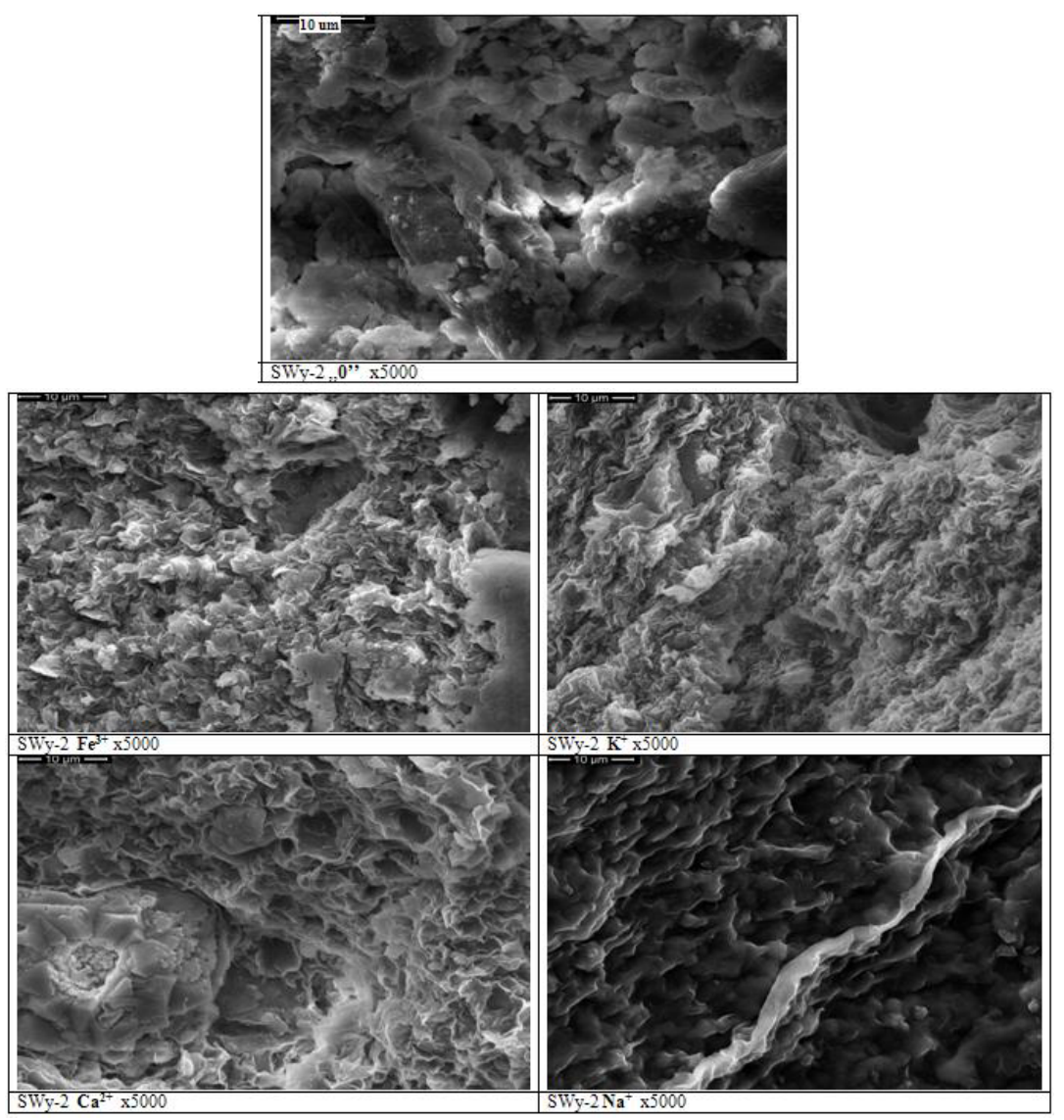

Fig. 4. SEM photographs of the natural SWy-2 bentonite and its' homoionic forms.

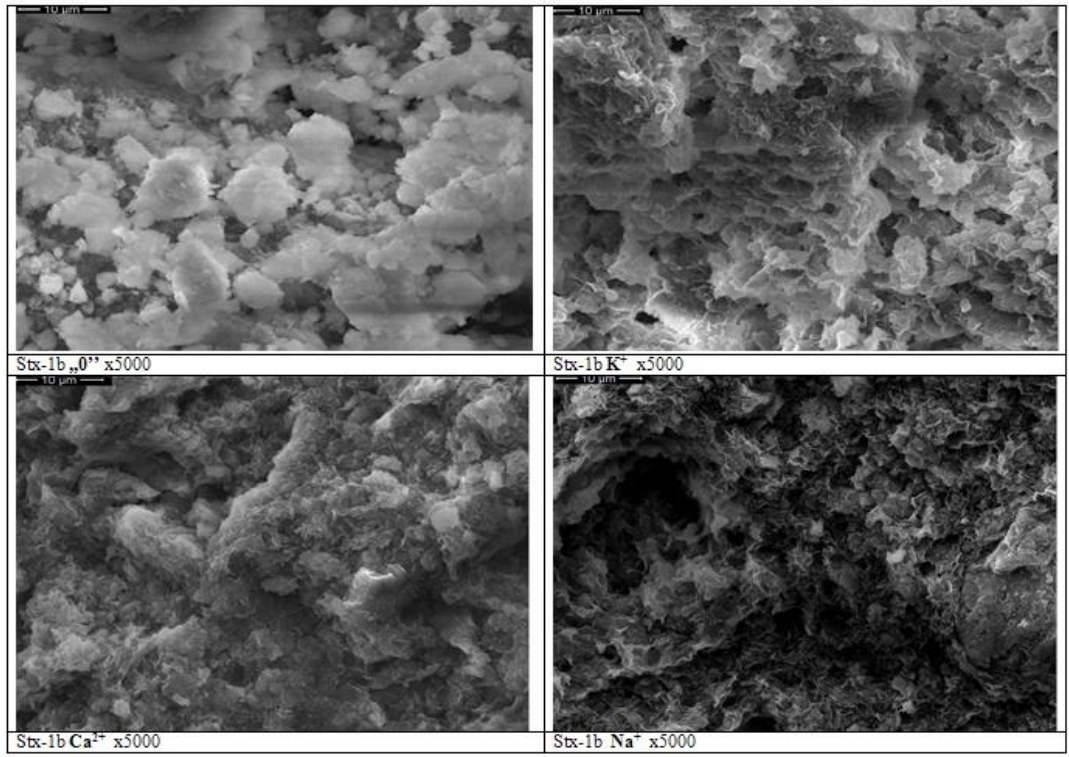

Fig. 5. SEM photographs of the natural Stx-1b bentonite and its' homoionic forms. 
The $\mathrm{K}^{+}$form of the BSvk bentonite was characterized by almost two-fold decrease of the total pore surface area and the number of micropores and 1.5 -fold increase in the number of ultrapores. In the case of $\mathrm{Ca}^{2+}$ form, there also was a two-fold decrease in the total pore surface area, but the number of ultrapores and micropores decreased respectively 2 and 3 times. For the $\mathrm{Na}^{+}$form, the following changes were observed: a small increase in the total pore surface area, a two-fold increase in the number of ultrapores, which probably occurred at the expense of reduced number of micropores.

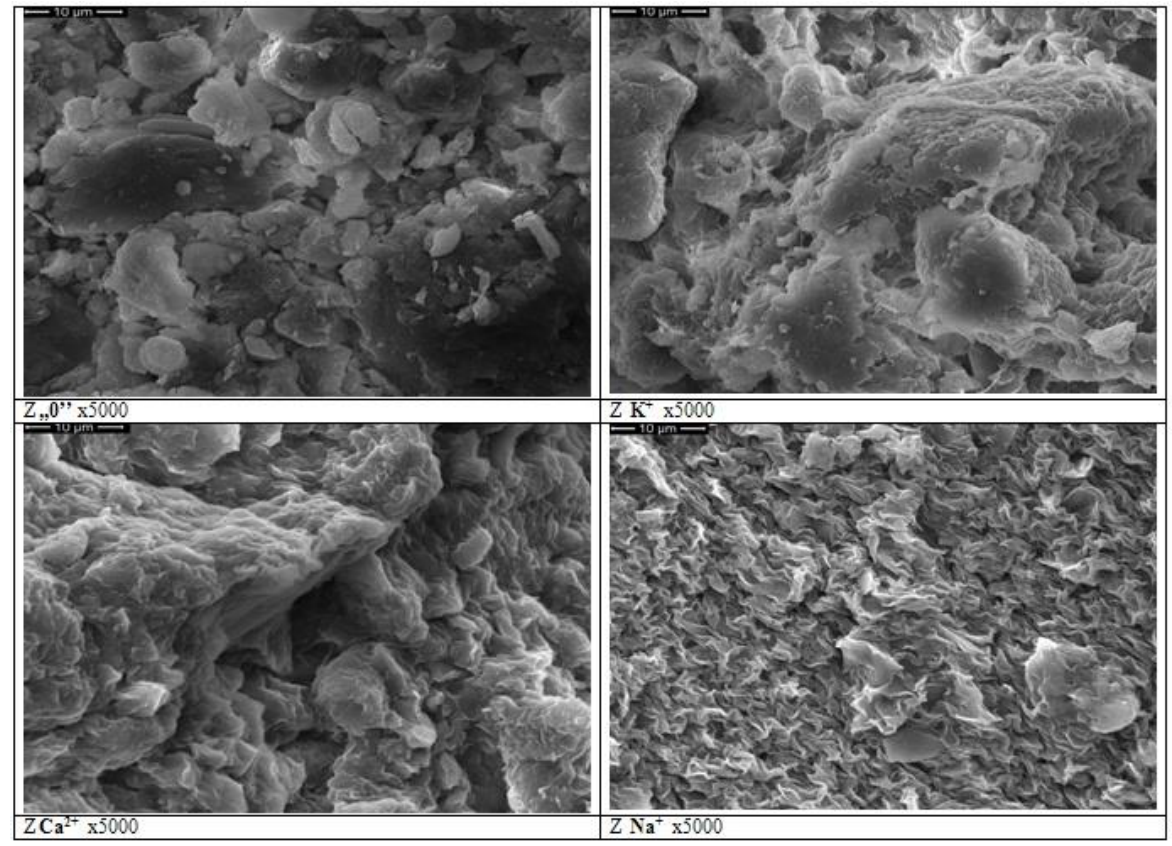

Fig. 6. SEM photographs of the natural BSvk bentonite and its' homoionic forms.

Furthermore, dependencies between pore structural parameters and the major cation $\left(\mathrm{Na}^{+}, \mathrm{K}^{+}, \mathrm{Ca}^{2+}, \mathrm{Fe}^{3+}\right)$ were found, regardless on the soil type. The observations are gathered in Table 4.

Table 4. Changes in structural parameters of the pores.

\begin{tabular}{|c|c|c|c|c|}
\hline \multirow{2}{*}{ Parameters } & \multicolumn{3}{|c|}{ The major cation in clays (SWy-2; Stx-1b, BSvk ${ }^{*}$ ) after ion exchange } \\
\cline { 2 - 5 } & $\mathrm{Na}^{+}$ & $\mathrm{K}^{+}$ & $\mathrm{Ca}^{2+}$ & $\mathrm{Fe}^{3+}$ \\
\hline $\begin{array}{c}\text { Total surface } \\
\text { area of pores } \\
{\left[\mu \mathrm{m}^{2}\right]}\end{array}$ & $\begin{array}{c}1.5 \text {-fold } \\
\text { decrease for } \\
\text { Stx-1b and 2- } \\
\text { fold increase for } \\
\text { SWy-2(higher } \\
\mathrm{Cl} \text { ) }\end{array}$ & $\begin{array}{c}2-3 \text { fold decrease } \\
\text { for BSvk and Stx- } \\
1 \mathrm{~b}^{* *}\end{array}$ & $\begin{array}{c}\text { 2-4 fold decrease } \\
\text { decrease }\end{array}$ & decrease \\
\hline $\begin{array}{c}\text { Total circuit } \\
\text { of pores }[\mu \mathrm{m}]\end{array}$ & $\begin{array}{c}1.5-3 \text { fold } \\
\text { increase }\end{array}$ & $\begin{array}{c}\text { decrease for BSvk } \\
\text { and Stx-1b } \\
\text { increase in SWy-2 } \\
\text { (higher Cl) }\end{array}$ & $\begin{array}{c}\text { 3-4 fold decrease for } \\
\text { BSvk and Stx-1b } \\
\text { (higher S, less Cl) }\end{array}$ & \\
\hline
\end{tabular}




\begin{tabular}{|c|c|c|c|c|}
\hline ultrapores & $\begin{array}{l}1.5-4 \text { fold } \\
\text { increase in } \\
\text { quantity }\end{array}$ & $\begin{array}{l}\text { 2-4 fold increase in } \\
\text { quantity in SWy-2 } \\
\text { and BSvk } \\
\text { and } 2 \text { fold decrease } \\
\text { for Stx-1b (higher } \\
\text { S) }\end{array}$ & $\begin{array}{l}2-2.5 \text { fold decrease in } \\
\text { quantity in BSvk and } \\
\text { Stx-1b } 4 \text { fold increase } \\
\text { in quantity }\end{array}$ & $\begin{array}{c}\text { 4-fold } \\
\text { increase }\end{array}$ \\
\hline micropores & $\begin{array}{l}\text { 2-3 fold } \\
\text { decrease in the } \\
\text { average area }\end{array}$ & $\begin{array}{l}\text { decrease in quantity } \\
\text { in BSvk and Stx- } \\
1 b^{* *} \text { decrease in the } \\
\text { average area for } \\
\text { BSvk and SWy-2 }\end{array}$ & $\begin{array}{l}\text { 1.5-3 fold increase in } \\
\text { quantity and the } \\
\text { average area for BSvk } \\
\text { and Stx-1b } 2.5 \text { - fold } \\
\text { decrease in the average } \\
\text { area for SWy-2 }\end{array}$ & $\begin{array}{l}\text { 2-fold } \\
\text { decrease in } \\
\text { quantity and } \\
\text { 3-fold the } \\
\text { average area }\end{array}$ \\
\hline
\end{tabular}

bentonite from Jelsovy Potok, Slovakia ${ }^{* *}$ soils have a similar the amount of clay fraction $(\mathrm{Cl})$ soils have a similar the specific surface area (S)

\section{Conclusions}

On the basis of the soil microstructure analysis, XRD results and physical properties comparison it can be assumed that the specific surface area of bentonite is related with the type of exchangeable cation. Because of that the specific surface area is connected with sorption capacity of the soil, the ion exchange in soils may be considered as a tool to control their properties.

In addition, the type of exchanged ion affects the d001 plane value. The XRD and SEM results indicate that the d001 planes have a close relationship with the number of pores in the soil. The increase in interplanar spacing d001 value causes an overall increase in the number of pores, in particular micropores. Decrease in d001 value leads to a reduced number of pores, in particular micropores.

A type of exchangeable cation has the influence on the pore structural parameters and physicomechanical parameters of the soil, but the type of the soil is not without importance and determines the intensity of changes after the ion exchange.

\section{References}

1. K. Clare, Road Research Laboratory Harmondsworth, Middlesex

2. A. R. Dexter and, K. Y Chant., Journal of Soil Science, 42, 219-226 (1991)

3. Solanki, P., and Zaman, M., Scanning Electron Microscope, V., In-Tech Publisher, Chapter 38, 771-798 (2012)

4. Y. M. Sergeyev, B. Grabowska-Olszewska, V. Opisov et al., Journal of Microscopy (1980)

5. B. Grabowska-Olszewska, Prz. Geol. 49, 299-302

6. T. Kozlowski, A. Rusin, E. Nartowska, Appl.Clay.Sci. (2014)

7. T. Kozlowski, E. Nartowska, Vadose Zone Journal (2013)

8. B. Grabowska-Olszewska, , Przegląd Geologiczny, 31, 162-165 (1983)

9. W. Chesworth, Encyclopedia od Soil Science, 476 (2007)

10. B. Grabowska-Olszewska, V. Opisov, V. Sokolov, Atlas of Microstructure of Clay Soils (1984) 